\title{
Kinetic Analysis of Lead Metabolism in Healthy Humans
}

\author{
Michael B. Rabinowitz, George W. Wetherinl, and Joel D. Kopple \\ From the Department of Planetary and Space Science, Schools of Medicine and \\ Public Health, University of California at Los Angeles, and Veterans \\ Administration, Wadsworth Hospital Center, Los Angeles, California 90073
}

\begin{abstract}
A в S T R A C T The steady state kinetics of lead metabolism were studied in five healthy men with stable isotope tracers. Subjects lived in a metabolic unit and ate constant low lead diets. Their intake was supplemented each day with 79-204 $\mu \mathrm{g}$ of enriched lead-204 as nitrate which was ingested with meals for 1-124 days. The concentration and isotopic composition of lead was determined serially in blood, urine, feces, and diet and less commonly in hair, nails, sweat, bone, and alimentary tract secretions by isotopic dilution, mass spectrometric analysis. The data suggest a three-compartmental model for lead metabolism. The first compartment encompasses blood and is 1.5-2.2 times larger than the blood mass. It contains approximately $1.7-2.0 \mathrm{mg}$ of lead and has a mean life of 35 days. This pool is in direct communication with ingested lead, urinary lead, and pools two and three. The second compartment is largely composed of soft tissue, contains about $0.3-0.9 \mathrm{mg}$ of lead, and has a mean life of approximately 40 days. This pool gives rise to lead in hair, nails, sweat, and salivary, gastric, pancreatic, and biliary secretions. Pool three resides primarily in the skeleton, contains the vast quantity of body lead, and has a very slow mean life. Bones appear to differ in their rates of lead turnover. Within the relatively small changes in blood lead observed in the present study, the transfer coefficients between the pools remained constant.
\end{abstract}

\section{INTRODUCTION}

The physiology of lead in humans is currently a subject of considerable interest engendered in part because of the potential toxicity of lead. Despite a number of recent

Dr. Rabinowitz was a National Institute of Environmental Health Science Fellow.

Dr. Wetherill's present address is Department of Terrestrial Magnetism, Carnegie Institution of Washington, 5241 Broad Branch Road, NW, Washington, D. C. 20015.

Address reprint requests to Joel D. Kopple. M. D., V. A. Wadsworth Hospital Center, Wilshire and Sawtelle Boulevards, Los Angeles, Calif. 90073.

Received for publication 21 July 1975 and in revised form 26 January 1976. studies, many aspects of normal lead metabolism are poorly understood. What is known is largely derived from the study of the time responses of lead levels in body tissues and fluids to changes in lead exposure and uptake. For example, Kehoe (1) and more recently Coulston et al. (2) have conducted a series of long-term studies in which healthy humans were exposed to increased quantities of lead in the diet or atmosphere. Observations in people with increased occupational exposure to lead have also provided data concerning these interrelationships (3). However, there is the possibility that the elevations in lead levels altered the lead physiology in these subjects. Studies involving tracers would enable lead metabolism to be investigated without increasing lead levels.

Hursh et al. have carried out studies with radioactive lead in humans $(4,5)$. These experiments involved the inhalation, ingestion, and injection of ${ }^{212} \mathrm{~Pb}$ which has a half-life of $10 \mathrm{~h}$. Hence, these studies were by necessity of short duration when compared with the characteristic transfer time of lead between major physiological pools.

We report here on the use of stable isotope lead tracers to examine the kinetics of lead metabolism in five healthy adult humans. This method has the advantage of allowing long-term observations without introducing radioactivity or altering lead exposure. A further analytical advantage is that problems from laboratory contamination could be minimized because the isotopic composition of the tracer lead utilized was distinguishable from the common lead in the environment.

\section{METHODS}

Five healthy adult male volunteers were maintained in a hospital metabolic unit for periods of 10-210 days. All subjects were apprised in depth of the nature of the experiment and gave informed consent. Subjects were fed diets constant in lead content which were prepared in the metabolic kitchen. In addition, at each meal and at the evening snack, a supplement of an enriched isotope of lead was ingested. The subjects' total daily lead intake was designed to approximate their prestudy levels as estimated from two 5-day fecal collections analyzed before the administration of 
TABLE I

Characteristics of the Subjects and Design of the Study

\begin{tabular}{lccccc}
\hline & \multicolumn{5}{c}{ Subject } \\
\cline { 2 - 6 } & A. & B. & C. & D. & E. \\
\hline Age, $y r$ & 53 & 49 & 27 & 25 & 26 \\
Weight, $k g$ & 70 & 89 & 88 & 58 & 84 \\
Average blood lead concentration, $\mu g / g$ & 0.25 & 0.18 & 0.17 & 0.20 & 0.17 \\
Days of study in the metabolic unit & 150 & 210 & 10 & 190 & 108 \\
Daily intake of tracer, $\mu g /$ day & 204 & 185 & 68 & 105 & 99 \\
Duration of intake of tracer, days & 104 & 124 & 1 & 83 & 10 \\
Usual dietary lead intake, $\mu$ g/day & 156 & 179 & 142 & 188 & 215 \\
\hline
\end{tabular}

* In some subjects collection of specimens was continued after they left the metabolic unit.

the lead supplement. Usually a tracer enriched with ${ }^{204} \mathrm{~Pb}$ (89\% pure) as nitrate was used (Oak Ridge National Laboratories, Oak Ridge, Tenn.). In three subjects, ${ }^{207} \mathrm{~Pb}$ (99.9\% pure) as nitrate was used for short periods of time as an additional tracer. After subjects ingested the daily dose of lead tracer, the vial which contained the tracer was rinsed twice with deionized water, and each wash was imbibed by the subject. On several occasions a vial was then rinsed with $6 \mathrm{~N} \mathrm{HNO}_{3}$, and the lead content of this rinse was measured; less than $0.1 \mu \mathrm{g}$ of lead was recovered in each washing.

Table I describes characteristics of the subjects, the experimental design, and the quantities of lead ingested. All subjects lived in a room air conditioned without filters to minimize perspiration. Prescribed physical activity was carried out daily. On the first day of the study subjects $A$. and $B$. decreased the quantity of cigarettes smoked from about 20 cigarettes to 8 cigarettes/day of a brand which was low in lead content to decrease respiratory intake of lead from cigarette smoke. Subject C. smoked 10 cigarettes/day of a popular brand. Subject D. smoked 20 cigarettes daily of a popular filtered brand for the first 40 days of the study and then stopped completely. Subject E. did not smoke. The lead content of the cigarettes smoked by the subjects before and after the onset of the study, their cigarette ashes, and the unsmoked butts were determined in our laboratory by isotope dilution analysis. On days 109,75 , and 40 of the study, respectively, subjects B., D., and E. entered a room with filtered, low-lead air and lived there for 40, 25, and 50 days, respectively. The changes in smoking habits and airborne lead exposure resulted in alterations in their total blood lead content.

During the study the total content and isotopic composition (IC) ${ }^{1}$ of lead were measured in all pooled specimens of urine and feces which were collected continuously, in diets which were prepared in duplicate at weekly intervals, and in whole blood which was collected serially. Feces and urine were each combined into 5-10 day pools. Fecal collections were demarcated with a brilliant blue marker. Blood was collected between 0800 and 0830 from subjects who were fasting since the previous midnight. During the long-term studies, total content and IC of lead were also measured periodically on facial and total body hair (including scalp), nails, induced sweat collected with a plastic body bag, saliva, and gastric, pancreatic, and biliary secre-

\footnotetext{
${ }^{1}$ Abbreviations used in this paper: EFS, endogenous fecal excretion; IC, isotopic composition.
}

tions collected by intubation. Pancreatic and biliary secretions were collected after stimulation with secretin and cholecystokinin according to previously described methods (6). In addition, several bone biopsies were obtained from subjects A. and B. from a location $2 \mathrm{~cm}$ below either iliac crest. Both cortical tables were removed during biopsy; specimens were immediately washed with saline and acetone, blotted dry, weighed, and then frozen with liquid nitrogen.

Certain specimens were also collected during periods when subjects were not receiving the tracer or were not ingesting a constant diet. Blood and facial hair were not uncommonly collected during such times.

Care was taken to avoid contamination during collection of all specimens. Before aspiration of gastrointestinal secretions, all tubing and flasks were washed with $6 \mathrm{~N} \mathrm{HCl}$ or $5 \% \mathrm{HNO}_{3}$ (distilled in Teflon) and rinsed with doubly distilled water. Hair samples were rinsed with $2 \% \mathrm{HNO}_{3}$ before spiking. Syringes, needles, and all specimen containers were demonstrated to elute insignificant quantities of lead (less than $0.1 \mu \mathrm{g}$ ).

The concentration and isotopic composition of lead in all specimens were determined by mass spectrometric isotope dilution analysis. Samples were spiked in the laboratory with known quantities of ${ }^{208} \mathrm{~Pb}$ before wet ashing with doubly distilled, concentrated $\mathrm{HNO}_{3}$ (lead content less than 0.7 parts per billion). Lead was extracted with a standard dithizone procedure and added to a silica gel and phosphoric acid mixture. This was loaded on a zone refined and vacuum heated rhenium filament in the thermal emission, solid source, mass spectrometer. Total blanks were typically $0.1 \mu \mathrm{g}$ of lead. The recovery of lead from spiked samples was determined twice and found to be $92 \%$ for blood and $87 \%$ for stool. For each analysis a minimum of 10 sets of isotope abundance ratios were collected; the standard deviations of these ratios were usually less than $0.5 \%$.

Certain details of the experimental design and methods of specimen handling in these studies and some aspects of the physiology of lead, such as gastrointestinal absorption, appearance in urine and hair, and compartmentalization within blood have been published previously (7).

Protein, energy, mineral, and vitamin content of the diets were designed to provide at least the minimum daily requirements for these nutrients. During the study, the mean estimated daily energy intake of the subjects was $34 \pm \mathrm{SD}$ $9 \mathrm{kcal} / \mathrm{kg}$. The dietary content of certain minerals was analyzed chemically in diets prepared in duplicate at 1-2 wk intervals as previously described (8). Subjects ingested 15 $\pm 2 \mathrm{~g}$ of nitrogen, $3,130 \pm 580 \mathrm{mg}$ of potassium, $1,240 \pm 50 \mathrm{mg}$ 
of calcium, $1,824 \pm 214 \mathrm{mg}$ of phosphorus, and $293 \pm 24 \mathrm{mg}$ of magnesium. Weight remained stable in all subjects throughout the study. It was concluded that protein and skeletal mass remained approximately constant during the study.

\section{RESULTS}

Summary of proposed model. A brief description of the proposed model of lead metabolism is given here to provide a framework for presentation of the results. A more detailed mathematical exposition of the model is given in the discussion. The IC of lead observed in the various tissues and fluids during the study can be understood in terms of a three-compartment model (Fig. 1 ), although it is likely that there are a multitude of physiological pools of lead.

Compartment one of the three-compartment model can be considered to include primarily blood and other tissues which are in rapid isotopic equilibrium with blood (Fig. 1). Kinetic analysis of the data indicates that this compartment contains about $1.9 \mathrm{mg}$ of lead and receives isotopically labeled lead from the gastrointestinal tract and unlabeled lead from the atmosphere. It exchanges lead with compartments two and three. Lead also moves from compartment one into the urine. Compartment two includes primarily soft tissues and possibly the more actively exchanging parts of the skeleton. It contains approximately $0.6 \mathrm{mg}$ of lead and gives rise to hair, nails, and at least some alimentary tract secretions. Compartment three includes the skeleton and, therefore, most of the lead in the body. The mean life of lead in pool one was $36 \pm 5$ days. In pool two the mean life varied from 30 to 55 days; in the third pool, it was much greater.

Compartment one. The observed concentrations of

\section{LEAD METABOLISM MODEL}

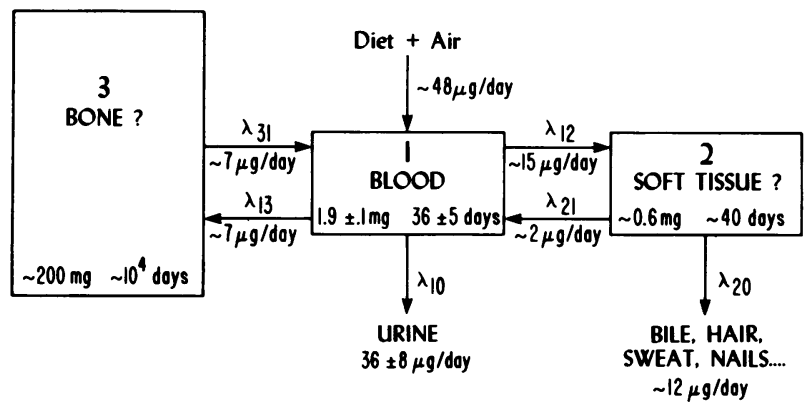

FIGURE 1 A three-compartmental model of human lead metabolism derived from tracer and balance data from five healthy men. The lead content and mean life of each pool and the rates of lead movement between pools ( $\lambda$ ) are shown. Numerical values represent the mean values $( \pm S D)$ for all subjects for whom data were available. Loss of lead from the body via pool two $\left(\lambda_{20}\right)$ is from integumentary structures (hair, nails, sweat) and alimentary tract losses, such as salivary, biliary, gastric, and pancreatic secretions.
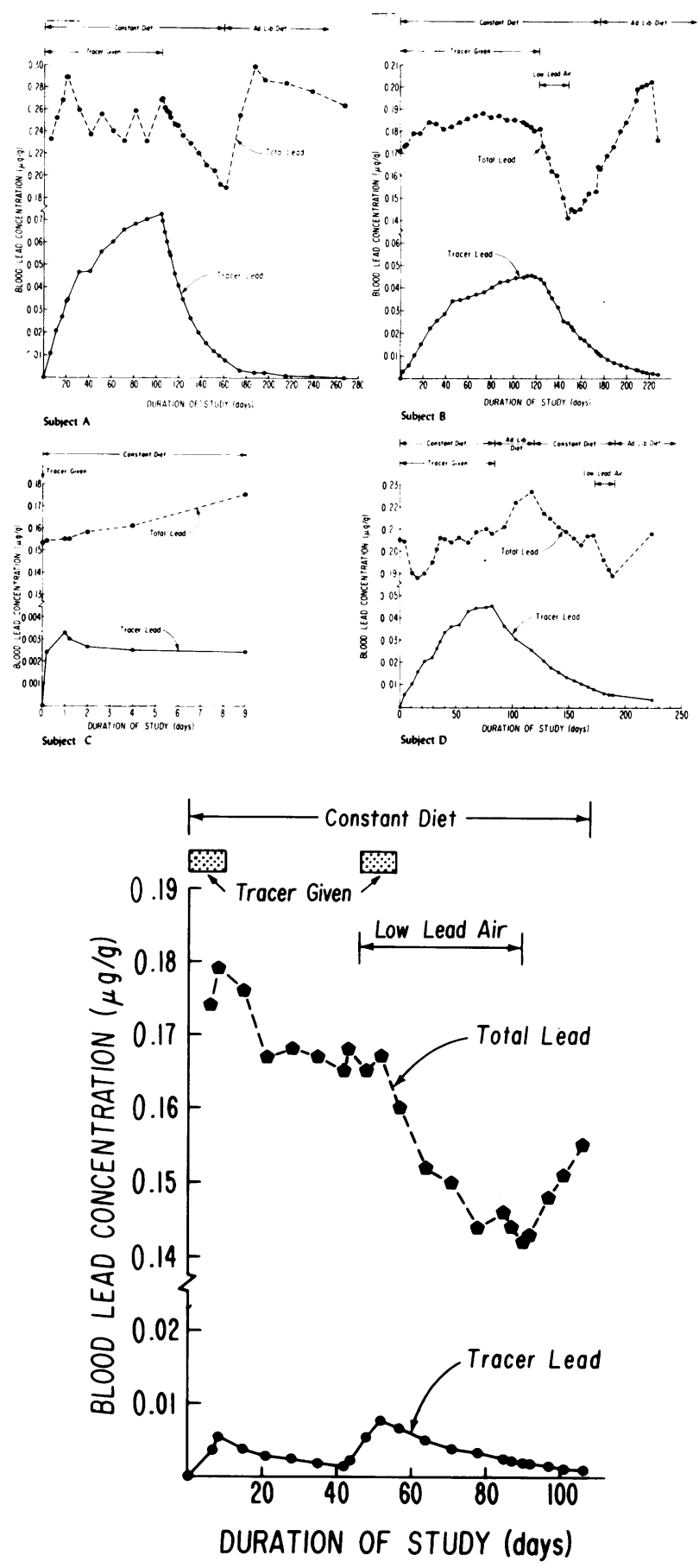

Subject $E$

Figure 2 Concentrations in whole blood of total lead and tracer lead in five healthy men during ingestion of constant low lead diets supplemented with lead tracer, the same diets without tracer, and ad lib diets. During certain periods of study, some subjects lived in a room with filtered low lead air (subjects B., D., and E.). Attention is called to the break in the vertical scale for each subject and the exaggeration in the magnitude of the vertical or horizontal scales in subjects $A$. and C. 
TABLE II

Size and Exchange Rates of First Pool

\begin{tabular}{lccccr}
\hline & \multicolumn{5}{c}{ Subject } \\
\cline { 2 - 6 } & A. & B. & C. & D. & E. \\
\hline Mass of first compartment, $\mathrm{kg}$ & 7.4 & 10 & 10.1 & 9.9 & 11 . $^{2}$ \\
Estimated blood volume, $\mathrm{kg}$ & 4.9 & 6.3 & 6.3 & 4.6 & 6.3 \\
Size of first pool, $\mu g$ & 1,860 & 1,820 & 1,718 & 1,993 & 1,890 \\
Mean life of first pool, days & 34 & 40 & 37 & 40 & 27 \\
Daily input or output from first pool, $\mu g /$ day & 54 & 45 & 46 & 50 & 70 \\
Fraction of output from first pool & & & & & \\
$\quad$ which goes to urine, $\%$ & 76 & 60 & 78 & 72 & 54 \\
Mean urinary output, $\mu g /$ day & 41 & 27 & 36 & 36 & 38 \\
\hline
\end{tabular}

tracer and total lead in pool one are shown in Fig. 2. The administered tracer appears rapidly in blood, and its concentration increases progressively. When the tracer is discontinued, the initial decrease in its abundance was abrupt. In the five subjects it was possible to assess the size and mean life of the pool of lead which was in rapid equilibrium with blood. This was done by fitting the observed changes in tracer lead concentrations in blood with a function containing two exponential terms (equation 8 , vide infra). The calculated values for the sizes and mean lives of this first pool in the five subjects are shown in Table II.

The mean urinary excretion varied from 27 to $41 \mathrm{\mu g} /$ day. From a comparison of the mean life and size of the first pool and the daily output of lead in urine, it can be calculated that $54-78 \%$ of the lead leaving the blood each day passes out of the body in urine (Table II). During the period of study, the IC of urinary lead, measured in urine pools collected for several days, closely resembled the IC of whole blood obtained during that time. Thus, within the time scale of sample collection utilized in the present study, it was not necessary to hypothesize any intermediate pools between blood and urine. Another small and well measured output of lead from the body is the volume of blood sampled periodically during the study. Accurate records of the volume of blood drawn during the course of study indicate that an average of 2.0-2.4 $\mathrm{mg}$ of total lead were removed by blood drawing each day. This represents about $4 \%$ of the daily output of lead from the first pool.

Compartment two. In contrast to lead lost from the body by urinary excretion and blood sampling, other bodily outputs of lead do not appear to be isotopically equilibrated with whole blood. As shown in Table III, sweat, hair, nails, and digestive secretions become labeled more slowly than blood. Although each substance has a different pattern of tracer uptake, they appear more like each other than like blood. This observation allows the simplifying assumption that for purposes of kinetic modeling, the origin of these various substances can be assigned to a common physiological pool, distinct from blood. The size and turnover rate of this second pool and its degree of coupling with the blood pool are obtained by fitting the tracer content of blood and the IC of the outputs from the second pool. Table IV shows the parameters of this deeper pool in the three subjects in whom measurements were made. This second pool appears to be smaller and to turn over more slowly than the first pool. Relatively little of the lead in the second pool is returned to blood. About a quarter of the daily amount of lead leaving blood goes to this second pool.

Compartment three. The quantity of lead calculated to reside in these two pools represents a small fraction of the $200 \mathrm{mg}$ of lead which is estimated to reside in the body, primarily in the skeleton (9). Hence a third physiological pool must be construed to exist. Three additional observations from the present study also suggest the existence of a third pool. During both ingestion of the lead tracers and after its discontinuation, the measured biological life of lead in blood is slightly shorter than the urinary and other bodily outputs (i.e., hair, nails, alimentary secretions, sweat) would suggest. This finding suggests the existence of another output of lead from blood. Further evidence for the existence of a third pool is derived from analysis of bone biopsied from the iliac crest (Table V). The tracer was observed in both the dense cortical tables as well as the spongy trabecular bone. It is of interest that the ratio of tracer to total lead was about two or three times greater in the trabeculae than in cortex suggesting a more rapid turnover of lead in trabecular bone. The abundance of tracer in the iliac biopsy was greater than would have been predicted from the estimated movement of tracer into bone and the calculated skeletal mass of the subjects. The rate at which lead moves into the skeleton is taken as the difference between the rate of lead output from pool one and the sum of the lead outputs from 
pool one to pool two and to urine (vide infra). The estimated movement of total lead from pool one to the skeleton was $9 \mu \mathrm{g} /$ day for subject A., $5 \mu \mathrm{g} /$ day for subject $B$., and $4 \mu \mathrm{g} /$ day for subject $D$. A comparison of these calculated rates with the observed concentrations of tracer lead in the iliac biopsies suggests that this portion of the skeleton received lead at approximately three to seven times the average rate of deposition of lead for this deepest body pool (Table V).

The third observation supporting the existence of a third pool is based on evidence indicating that lead moves from the skeleton to blood. After discontinuing ingestion of the lead tracer, its concentration in the blood does not decrease as rapidly toward zero as would be predicted from a two-pool model. In contrast, the data suggest that there is an internal long-lived source of the tracer. These data were derived from the three subjects who received the tracer for the longest periods of time. The rates of fall of their blood lead tracer after its administration was discontinued as shown in Fig. 3. The evidence for the existence of the input from a third pool is seen most clearly in subject A. His blood tracer concentration had decreased to $0.004 \mu \mathrm{g} / \mathrm{g} 163$ days after the dietary tracer was discontinued. This

TABLE III

Lead from Deeper Body Pools

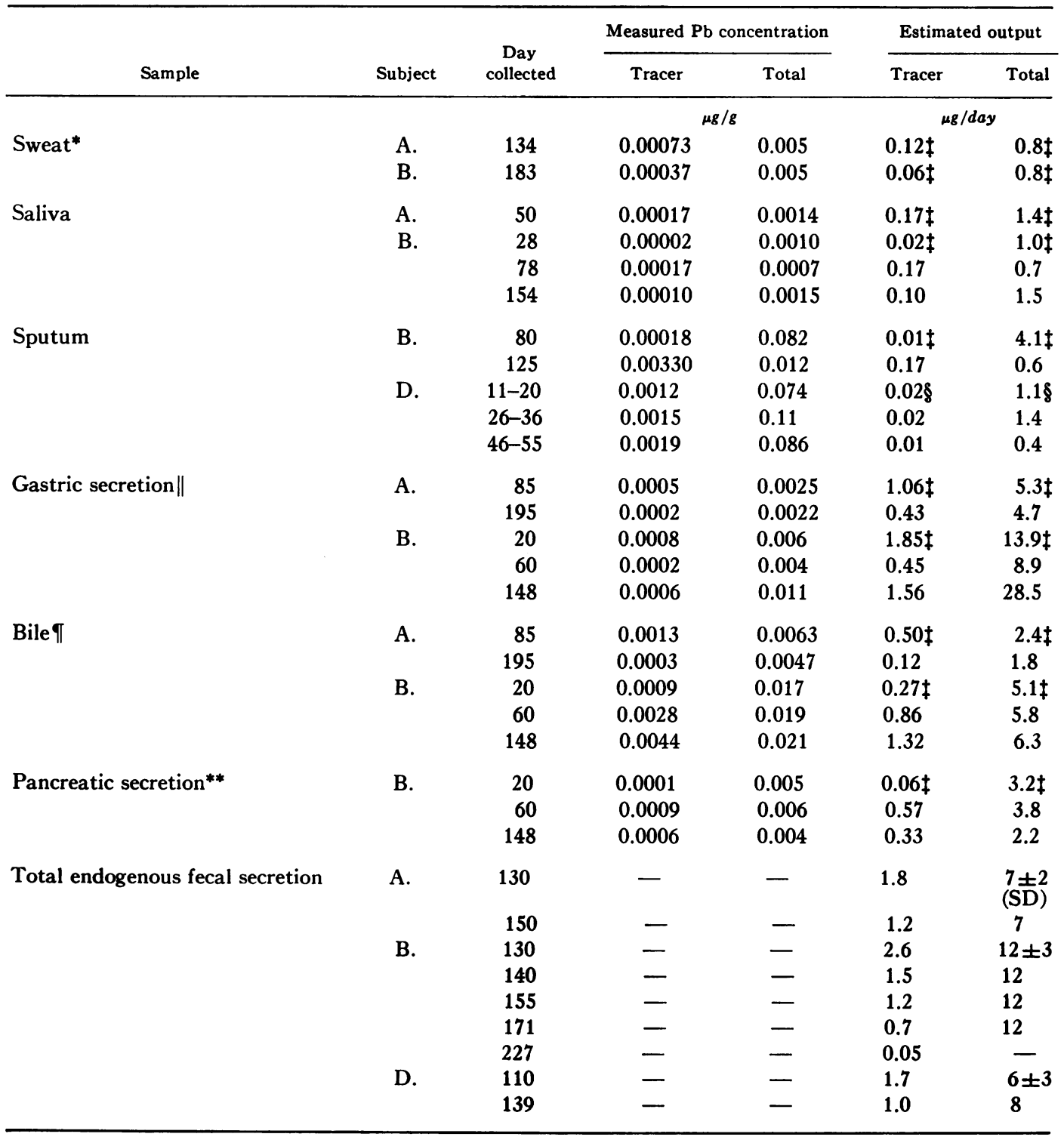


TABLE III-(Continued)

\begin{tabular}{|c|c|c|c|c|c|c|}
\hline \multirow[b]{2}{*}{ Sample } & \multirow[b]{2}{*}{ Subject } & \multirow{2}{*}{$\begin{array}{c}\text { Day } \\
\text { collected }\end{array}$} & \multicolumn{2}{|c|}{ Measured $\mathrm{Pb}$ concentrations } & \multicolumn{2}{|c|}{ Estimated output } \\
\hline & & & Tracer & Total & Tracer & Total \\
\hline & & & & & & \\
\hline \multirow[t]{3}{*}{ Nails§ (toe and finger) } & A. & 120 & - & 8.9 & 0.0004 & 0.07 \\
\hline & B. & 60 & - & 22 & 0.0036 & 0.7 \\
\hline & E. & 20 & - & 13 & - & - \\
\hline \multirow[t]{14}{*}{ Hair§ (facial) } & A. & 40 & 0.05 & 16.7 & 0.0036 & 1.2 \\
\hline & & 104 & 0.48 & 11.8 & 0.045 & 1.1 \\
\hline & & 153 & 1.00 & 15.7 & 0.089 & 1.4 \\
\hline & & 181 & 0.35 & 16.1 & 0.03 & 1.4 \\
\hline & B. & 75 & 0.32 & 14.5 & 0.04 & 1.8 \\
\hline & & 120 & 0.55 & 13.2 & 0.05 & 1.2 \\
\hline & & 220 & 0.54 & 11.9 & 0.05 & 1.1 \\
\hline & D. & 35 & 0.04 & 24.7 & - & - \\
\hline & & 70 & 0.15 & 16 & - & - \\
\hline & & 105 & 0.34 & 18.3 & - & - \\
\hline & & 125 & 0.6 & 17.3 & - & - \\
\hline & & 150 & 0.36 & 16.6 & - & - \\
\hline & & 177 & 0.24 & 17.8 & - & - \\
\hline & & 185 & 0.06 & 15.3 & - & - \\
\hline \multirow[t]{2}{*}{ Total body hair§ } & A. & $5-105$ & - & 16.3 & - & 3.4 \\
\hline & B. & $10-179$ & - & 12.2 & - & 2.7 \\
\hline
\end{tabular}

* Collected during induced profuse sweating.

$\ddagger$ Derived from standard estimates of volume produced each day.

$\$$ Daily outputs based on collection of entire specimen.

\| Collected under basal resting conditions.

T/ Collected after administration of cholecystokinin.

** Collected after administration of secretin.

quantity is close to the value of $0.005 \mu \mathrm{g} / \mathrm{g}$ which is predicted from a two-pool model. However, when samplings were continued for a more extended period, the observed values exceeded the concentrations predicted by the two-pool model. After discontinuation of the tracer for 303 days, the blood tracer was $0.002 \mu \mathrm{g} / \mathrm{g}$, while the two-pool model predicted $0.000008 \mu \mathrm{g} / \mathrm{g}$. This additional concentration of tracer can be accounted for by postulating an input of $0.054 \mu \mathrm{g} /$ day of lead tracer.

Utilizing these inputs of tracer lead to blood, the IC of skeletal lead, as estimated from the calculated loss of tracer from blood to bone (vide supra), and the

TABLE IV

Parameters of Second Physiological Pool

\begin{tabular}{|c|c|c|c|}
\hline & \multicolumn{3}{|c|}{ Subject } \\
\hline & A. & B. & D. \\
\hline $\begin{array}{l}\text { Pool size, } \mu g \\
\text { Mean life, days } \\
\text { Daily input or output, } \mu g / \text { day } \\
\text { Fraction of output which }\end{array}$ & $\begin{array}{c}260 \pm 100(\mathrm{SD}) \\
30 \pm 4 \\
9 \pm 4 \\
28\end{array}$ & $\begin{array}{c}900 \pm 100 \\
38 \pm 12 \\
24 \pm 8\end{array}$ & $\begin{array}{c}550 \pm 100 \\
55 \pm 15 \\
10 \pm 3\end{array}$ \\
\hline goes to first pool, \% & 28 & 6 & 8 \\
\hline
\end{tabular}

predicted total lead content of the skeleton, a total of about 6-10 $\mu \mathrm{g}$ of lead can be calculated to move each day from bone to blood. Thus, the changes in concentration of the blood tracer after initiating (vide supra) and terminating intake of the tracer indicate that the rate of movement of lead into and out of the skeleton

TABLE V

Lead in Biopsied Iliac Bone and Total Skeleton

\begin{tabular}{lll}
\hline & \multicolumn{2}{c}{ Subject } \\
\cline { 2 - 3 } & A. & B. \\
\hline $\begin{array}{l}\text { Trabeculae, } \mu g / g^{*} \\
\text { Lead tracer }\end{array}$ & 0.075 & 0.045 \\
$\quad \begin{array}{l}\text { Total lead } \\
\text { Cortex, } \mu g / g^{*} \\
\quad \text { Lead tracer } \\
\quad \text { Total lead }\end{array}$ & 7.83 & 4.49 \\
$\begin{array}{l}\text { Estimated tracer lead in total skeleton, } \mu g \\
\text { Extrapolation from tracer concentrations } \\
\text { in bone biopsies }\end{array}$ & 0.049 & 0.054 \\
$\quad$ Extrapolations from output of & 14.9 & 9.10 \\
$\quad$ tracer from blood & 702 & \\
\hline
\end{tabular}

* Concentrations are expressed on a fresh weight basis. 


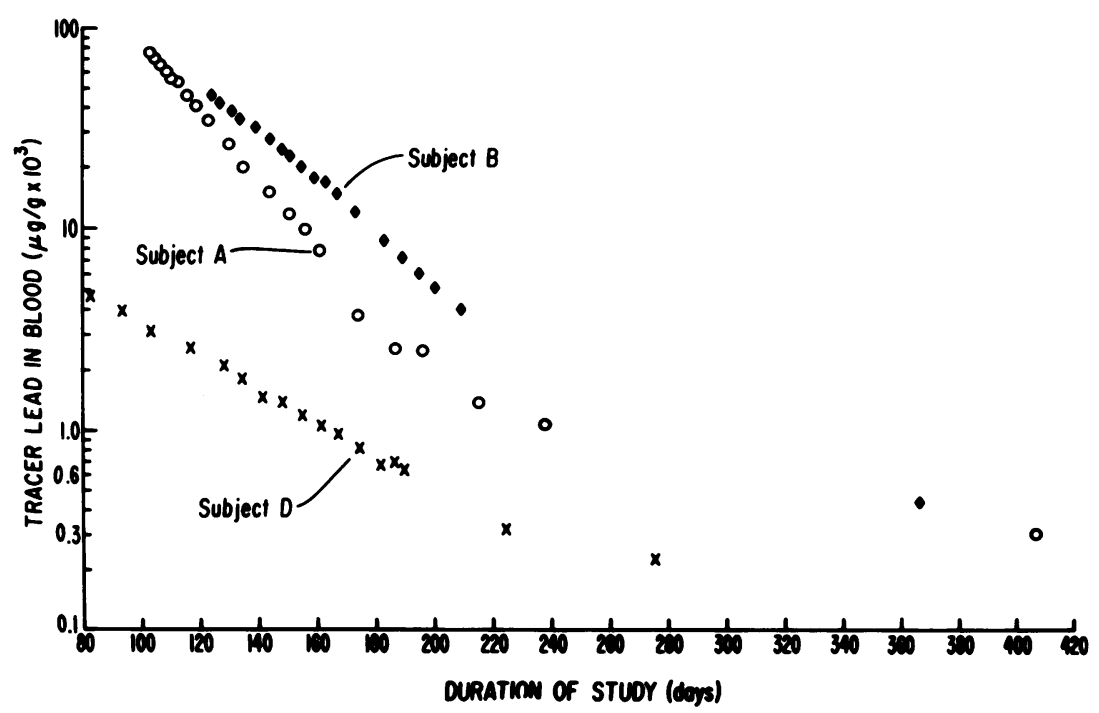

FIGURE 3 The rate of fall of tracer lead in blood after the tracer dosage was discontinued in three subjects undergoing long term studies. The first blood level depicted for each subject indicates the beginning of the first day without tracer. The data are presented logarithmically, and the changes in the slopes provide evidence that tracer lead is entering blood from deeper body pools.

was approximately the same. These estimations of lead movements, which were made by two sets of relatively independent observations, suggest that lead balance for the skeleton was within about $4 \mu \mathrm{g} /$ day of equilibrium.

Intestinal absorption and excretion of lead. The rates of absorption of lead tracer from the gastrointestinal tract were determined by measuring the difference between intake and fecal output of tracer lead after correcting the output for endogenous fecal excretion (EFS) (Table VI). Knowledge of real absorption (input plus EFS minus output) is necessary to assess the magnitude of body lead pools and rate constants. Initially, no tracer lead is excreted by the body into the feces because the source of these secretions has not yet become labeled. Hence, only unlabeled lead is secreted. Thus adjustment of calculated absorption of tracer lead for EFS is initially nil. However, after a few months of continuous tracer intake, bile and gastrointestinal secretions were found to contain appreciable amounts of tracer lead (vide supra), and EFS of tracer lead at this point may have contributed up to a few micrograms per day to total fecal output of tracer.

The calculated amount of tracer lead in feces which is derived from unreabsorbed lead in bile and other bodily sources rather than from unabsorbed tracer lead is based on a model-dependent extrapolation of two observed quantities: (1) the tracer lead content of specific gastrointestinal secretions measured on a few occasions and (2) the delayed disappearance of the tracer from feces after its discontinuation from the diet. The former set of measurements indicates how the relative amounts of tracer and total lead in the secretions change with time. Moreover, these measurements can be used to estimate the total daily lead output. However, these mea-

TABLE VI

Intestinal Absorption and Excretion of Lead Tracer

\begin{tabular}{|c|c|c|c|c|c|}
\hline & \multicolumn{5}{|c|}{ Subject } \\
\hline & A. & B. & c. & D. & E. \\
\hline${ }^{204} \mathrm{~Pb}$ Tracer intake, $\mu \mathrm{g} /$ day of lead tracer & $204.4 \pm 0.2(\mathrm{SD})$ & $185 \pm 0.03$ & $67.8 \pm 0.03$ & $104.8 \pm 0.03$ & $99.1 \pm 0.03$ \\
\hline Fecal output, $\mu g /$ day of lead tracer & $183.3 \pm 1.3$ & $174 \pm 0.8$ & $58.5 \pm 1.2$ & $94 \pm 1.4$ & $90.1 \pm 1.1$ \\
\hline Endogenous excretion, $\mu g /$ day of lead tracer & $1 \pm 0.3$ & $1 \pm 0.2$ & 0 & $0.6 \pm 0.3$ & 0 \\
\hline Quantity of tracer absorbed, ${ }^{*} \mu \mathrm{g} /$ day of lead tracer & $17.5 \pm 1.5$ & $12 \pm 1$ & 9.3 & $11.4 \pm 1.4$ & $9.0 \pm 1.1$ \\
\hline Percent of tracer absorbed* & $8.5 \pm 0.7$ & $6.5 \pm 0.5$ & 13.7 & $10.9 \pm 1.3$ & $9.1 \pm 1.1$ \\
\hline
\end{tabular}

* Corrected for the endogenous excretion of tracer (see text). 
surements represent only a few accessible sources of EFS (salivary, gastric, biliary, and pancreatic) collected under conditions of stimulated secretion (Table III). In contrast, the delayed disappearance of tracer from feces can be used to calculate the amount of tracer lead which is excreted from all internal sources of fecal lead.

In two subjects (A. and B.), a second isotope tracer, ${ }^{207} \mathrm{~Pb}$ as the nitrate, was administered for 10 days each to differentiate between endogenous excretion of lead tracer and delayed passage of unabsorbed tracer. Ingestion of ${ }^{207} \mathrm{~Pb}$ and the first tracer, enriched in ${ }^{200} \mathrm{~Pb}$, were discontinued concurrently. Fecal excretion of the second tracer was not detectable 20 days after it was discontinued. Hence, excretion of the first tracer more than 20 days after ingestion was terminated was considered to represent endogenously excreted lead. In the three subjects for whom EFS was reported (Tables III and VI), EFS of tracer lead was determined in specimens collected more than 20 days after stopping the tracer. In these calculations, the assumption is made that the rate of reabsorption of endogenously excreted lead is similar to that of ingested lead nitrate tracer.

\section{DISCUSSION}

The formula which was used to describe this model was based upon the following considerations: the rates of change of the concentrations of a set of isotopically identifiable species of lead in each of a group of interconnected compartments can be expressed in terms of a set of coupled first order differential equations. One such equation is as follows:

$$
\frac{\mathrm{dX}_{\mathrm{i}}}{\mathrm{dt}}=\frac{A_{\mathrm{i}}}{M_{\mathrm{i}}}-\lambda_{\mathrm{i}} X_{\mathrm{i}}+\underset{\mathrm{j}}{\Sigma} \lambda_{\mathrm{ji}} X_{\mathrm{j}} \frac{M_{\mathrm{j}}}{M_{\mathrm{i}}}
$$

Where $X_{1}$ is the concentration of a species in compartment i $(\mu \mathrm{g} / \mathrm{g})$

$M_{1}$ is the mass of compartment i $(\mathrm{g})$

$A_{1}$ is the rate at which species $X$ enters compartment i directly from outside the body ( $\mu \mathrm{g} /$ day)

$\lambda_{1}$ is the rate constant for the movement of lead either into or out of compartment $\mathrm{i}\left(\mathrm{day}^{-1}\right)$. It is the reciprocal of the mean residence time for lead in the compartment.

$j$ refers to each pool other than $i$

$$
M_{\mathbf{j}} \underset{\mathbf{i}}{\Sigma} X_{\mathrm{i}}
$$

is the quantity of lead in pool $j$ (i.e., its size) $\lambda_{11}$ is the rate constant for movement from compartment $j$ to $i$ $\left(\right.$ day $\left.^{-1}\right)$ with the notation that

$$
\lambda_{i}=\sum_{j=0}^{\sum} \lambda_{i j}
$$

This set of expressions has the form of linear equations.
However, insofar as the total lead content is maintained constant, the application of equation (1) to the modeling of lead metabolism is not based upon the assumption that the flow of lead into or out of a compartment varies linearly with the lead level. Rather it is only assumed that the relative amounts of the various isotopes of lead leaving a compartment are proportional to their relative abundances inside the compartment. In other words, a biological compartment or system would not be able to distinguish one isotopic species from another or handle them differently. Development of this model is also based on the assumption that the sizes of the pools are constant during the period of study, i.e., there is mass equilibrium. As discussed in Methods, clinical evaluation and dietary intake of the subjects suggested that the protoplasmic and skeletal mass of the subjects were in neutral balance. The $\lambda$ 's are considered to be independent of time. In addition, the model appears to fit the experimental data equally well over the range of concentrations of lead found in the present study (vide infra). Hence for this study the $\lambda$ 's are also considered to be independent of the total lead content in a compartment. However, it is possible that with a wider range of lead concentrations the $\lambda$ 's may vary. As is usual with compartmental analysis, a compartment or pool is considered to be isotopically well mixed.

Because of the slow turnover of compartment three, only a negligible quantity of tracer lead from this pool moves back into blood during the course of the experiment. For the first $100-200$ days of each experiment, compartment three can therefore be considered as a time-independent source of normal lead and as a sink for labeled lead. According to the design of this study, only compartment one receives the lead tracer directly from outside the body. These findings allow equation (1) to be simplified. Thus, the differential equations for the change in the concentrations of tracer lead in two timedependent compartments (one and two) would become

$$
\begin{aligned}
& \frac{\mathrm{dX}_{1}}{\mathrm{dt}}=\frac{A}{M_{1}}-\lambda_{1} X_{1}+\lambda_{21} \frac{M_{2}}{M_{1}} \mathrm{X}_{2} \\
& \frac{\mathrm{dX}}{\mathrm{dt}}=\frac{M_{1}}{M_{2}} X_{1} \lambda_{12}-\lambda_{2} X_{2}
\end{aligned}
$$

Equations (3) and (4) can be more conveniently expressed in terms of the measurable blood lead concentration $X_{\mathrm{b}}$ by substituting $X_{\mathrm{b}}=\frac{\mathrm{X}_{1}}{\mathrm{~K}}$ where the scale factor $K$ is the ratio of the mean concentration of lead in compartment one to that in blood.

General solutions to equations (3) and (4) have been derived giving $X$ 's as a function of time in terms of $\lambda$ 's, 
$M$ 's, and $A$; they are of the form

$$
\begin{aligned}
& X_{\mathrm{b}}=C_{11} \mathrm{e}^{-\mathrm{r}_{1} \mathrm{t}}+C_{12} \mathrm{e}^{-\mathrm{r}_{2} \mathrm{t}}+C_{13} \\
& X_{2}=C_{21} \mathrm{e}^{-\mathrm{r}_{1} \mathrm{t}}+C_{21} \mathrm{e}^{-\mathrm{r}_{2} \mathrm{t}}+C_{23}
\end{aligned}
$$

The coefficients $C$ are known functions of the parameters, $\lambda$ 's, $M$ 's and $A$, and the initial conditions, and $\mathrm{r}_{1}$ and $r_{2}$ are the roots of the quadratic

$$
\left(\mathrm{r}-\lambda_{1}\right)\left(\mathrm{r}-\lambda_{2}\right)-\lambda_{12} \lambda_{21}=0
$$

In general when $\mathrm{t}=0, X_{\mathrm{b}}=X_{0}$, and $X_{\mathrm{a}}=Y_{\mathrm{o}}$, equation (5) would become

$$
\begin{aligned}
X_{\mathrm{b}}= & \frac{1}{\left(\mathrm{r}_{1}-\mathrm{r}_{2}\right)}\left\{\left[\left(\mathrm{r}_{1}-\lambda_{2}\right)\left(X_{0}-\frac{A}{M_{1} K \mathrm{r}_{1}}\right)\right.\right. \\
& \left.-\frac{M_{2}}{M_{1} K} \lambda_{21} Y_{0}\right] \mathrm{e}^{-\mathrm{r}_{1} \mathrm{t}}+\left[\left(\lambda_{2}-r_{2}\right)\right. \\
& \left.\left.\times\left(X_{0}-\frac{A}{M_{1} K r_{2}}\right)+\frac{M_{2}}{M_{1} K} \lambda_{21} Y_{0}\right] \mathrm{e}^{-\mathrm{r}_{22} \mathrm{t}}\right\} \\
& +\frac{A}{M_{1} K} \frac{\lambda_{2}}{\mathrm{r}_{1} \mathrm{r}_{2}}
\end{aligned}
$$

The observed concentrations of the tracer lead in blood and other tissues and fluids enable one to apply equation (8) and an analogous equation for compartment two to calculate the pool sizes, mean lives, and exchange constants as described in the results. Table VII indicates the measured concentrations of tracer lead in blood of the five subjects and the predicted values for each specimen calculated from the compartmental model described in equation (8).

It should be emphasized that during ingestion of the lead tracer, the changing concentrations of tracer in blood could be adequately described by a two pool model. In this simplified model, the second and third pools would be combined. In the present study, the data which distinguished the second from the third pools were (1) the changing rates of disappearance of the tracer lead from blood after discontinuing the tracer and, more importantly, (2) the observation that the IC of lead in hair, nails, and alimentary tract secretions did not resemble that in either blood or bone. Indeed, it was not possible to distinguish three distinct pools in the two subjects who were studied less extensively.

As previously mentioned the calculated combined amount of total lead in pools one and two is approximately $3 \mathrm{mg}$. This is markedly less than the $10-30 \mathrm{mg}$ of lead found in soft tissues at autopsy (9). This finding indicates that most of the lead in soft tissues does not exchange with blood during the several-hundred-day period of study. Hence, according to the three pool model, this nonexchangeable soft tissue lead would be consigned to the third pool. In the present study, there was no relation between the quantity of lead in pools one and two and the age of the subjects. These findings are consistent with those of Schroeder and Tipton that soft tissue lead content does not vary closely with age (9).

The size of the first, most labile, compartment is 1.5-2.2 times the estimated blood mass, and accounts for $11-17 \%$ of the body mass of the subjects. The mean life of pool two is appreciably shorter than the mean life of the red cell, about 120 days (10). Since approximately $90 \%$ of the lead in blood resides in red cells (11), it may be inferred that lead enters and leaves red cells several times during their lives. The results from the present study and other data concerning tracer lead in blood and urine (11) support this concept. Urine and blood lead are essentially in isotopic equilibrium (12), and since most of the lead in urine is probably filtered (13), it seems evident that lead may readily enter and leave the red cell. In vitro studies have also shown a rapid uptake of tracer lead by erythrocytes (14).

There is an important question concerning the extent to which values for the rate constants ( $\lambda$ 's) for lead transfer are dependent on blood levels, degree of exposure, or body burden of lead. Although the present study was designed so that blood lead levels would not vary greatly, the data provide some evidence that these rate constants are independent of changes in blood lead levels over at least a small range of values.

In subject $B$., the blood lead decreased to 0.15 and then increased to $0.18 \mu \mathrm{g} / \mathrm{g}$ between days 130 and 180 (Fig. 2). During this time, the biological decay rate for the tracer in blood remained fairly constant as seen by the slope in Fig. 2. Similarly for subject D., the blood lead fell to 0.205 and rose to $0.225 \mu \mathrm{g} / \mathrm{g}$ between days 90 and 180 while the tracer disappeared at a constant rate. In no subject did the transfer coefficients appear to vary during alterations in blood lead concentrations. Hence, it may be inferred from these observations that within the range of commonly found blood lead concentrations, changes of $10-20 \%$ do not observably alter the rate constants. These findings as well as previously reported data (11) indicate that the blood lead and the quantities of lead absorbed from the gastrointestinal tract, excreted in urine, and transferred to deeper body pools vary linearly with dietary lead exposure.

Tola et al. have described the response of blood lead to excessive occupational lead exposure (3). It is of interest that they found the characteristic time for the elevation of blood lead levels to be approximately $1 \mathrm{mo}$. This corresponds closely to the mean life of the first pool observed in the present study, about 35 days. Thus, the transfer coefficients for lead observed in this study may remain constant over a much wider range of blood lead levels.

It is of interest that in the present study the lead con- 
TABLE VII

Observed and Predicted* Concentrations of Tracer Lead in Blood

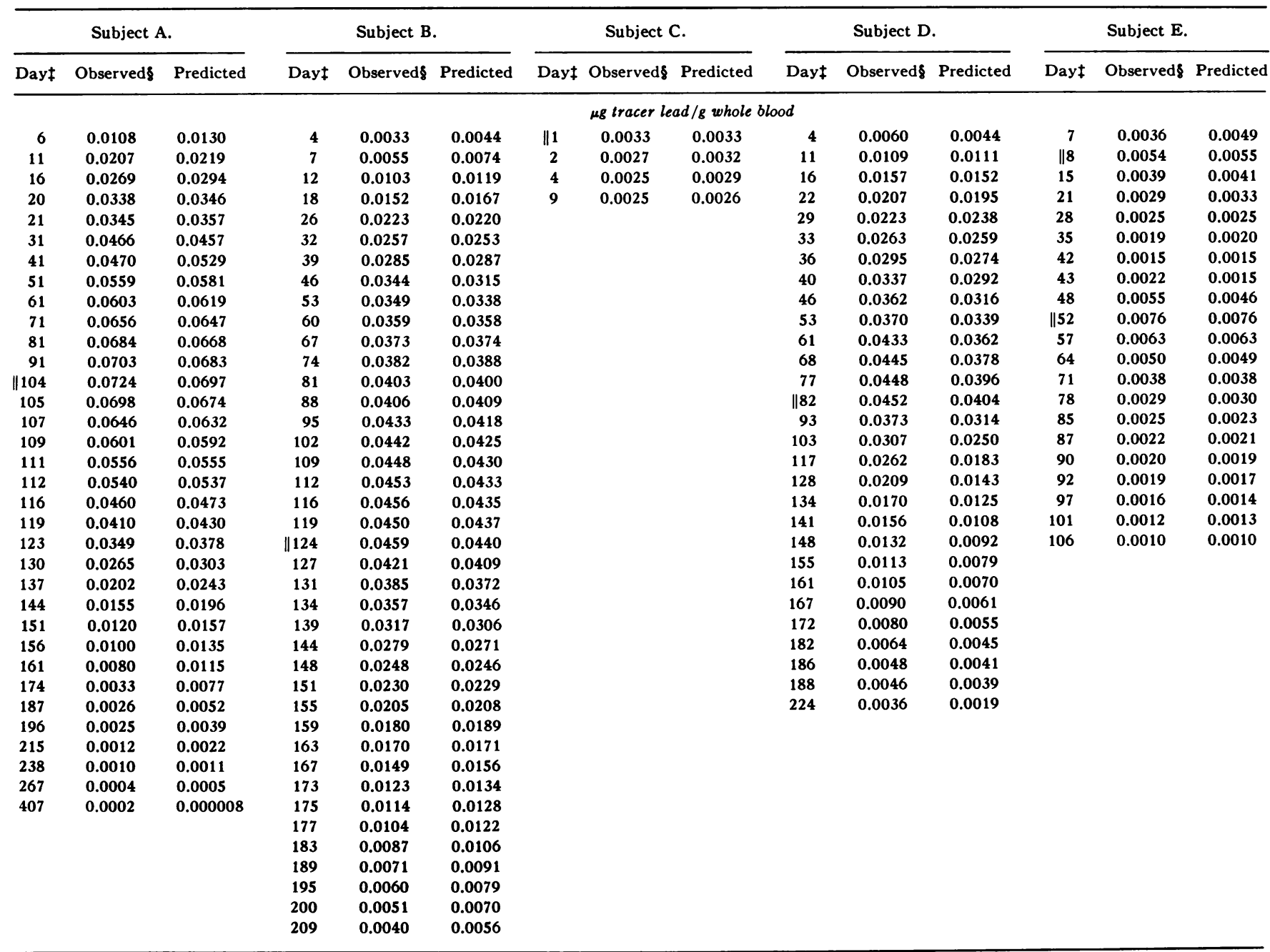

* Predicted from the mathematical model of lead metabolism (see text).

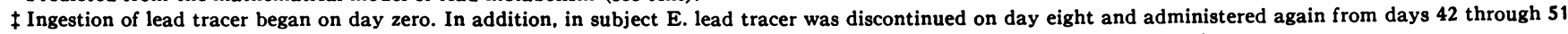
Each observed value was analyzed in blood which was drawn in fasting subjects between 0800 and 0830 on the indicated day.

\| Tracer discontinued after blood was drawn on this day.

centrations in sweat were determined to be about $7 \mu \mathrm{g} / 1$ which is about $20 \%$ of the concentration in urine. This finding is in contrast with previous reports that the lead levels in sweat and urine are equal (15). The present data also indicate that in contrast to previous comments (15) salivary, gastric, pancreatic, and biliary secretions all contribute to the excretion of lead in the alimentary tract. The product of the respective lead concentrations and the predicted daily volume of each of these secretions (16) indicates that the gastric juice may be a major source of endogenous fecal excretion (Table III). It is possible that these results may not completely reflect the normal state as secretin and cholecystokinin were used to stimulate secretions. More- over despite careful collection techniques, saliva is particularly subject to contamination from the urban atmosphere.

The results of this study differ markedly from the pattern of lead handling reported in rodents. Rats were studied after a single intravenous injection of ${ }^{20} \mathrm{~Pb}$ $(17,18)$. After injection, there was a more rapid clearance of lead from blood, with an excretion coefficient of $0.2 / \mathrm{h}$. In contrast to adult humans, more lead was excreted in feces and transferred into the skeleton. These differences may be a result of the design of the experiment; the rats received $25-250 \mu \mathrm{g}$ of lead carrier, which may have greatly altered the normal physiological handling of lead and affected red cell survival. In other 
experiments where rats and hamsters inhaled radioactive lead (19), the bodily distribution of tracer lead was found to differ from humans. The animals had a higher percentage of the administered tracer in the kidneys and only half as much in erythrocytes as compared to humans. Their clearance of lead from blood was also more rapid.

In these latter studies the total lead intake was not substantially increased, and therefore their lead metabolism was probably not perturbed. Hence, these observations may indicate a difference between rodents and humans in the physiological handling of lead.

\section{ACKNOWLEDGMENTS}

This work was supported by a National Science Foundation (RANN) grant GI-38339. The project is the Veterans Administration protocol number 5016-02. Alice Lichtenstein assisted in the chemical analysis and Mark Stein maintained and upgraded the mass spectrometer. Ann Chance, Shirley McKay, Nora Hechanova, Dorothy Mulcare, Robert Adachi, John Lee, and Herbert Dennin provided invaluable technical support.

Appreciation is expressed to the experimental volunteers for their enthusiastic participation in the study.

\section{REFERENCES}

1. Kehoe, R. 1961. The metabolism of lead under abnormal conditions. J. R. Inist. Public Health Hyg. 24: 101-143.

2. Coulston, F., L. Goldberg, and T. Griffin. 1973. The effects of continuous exposure to airborn lead IV. Exposure of men to particulate lead at a level of 3.2 $\mu \mathrm{g} /$ cubic meter. Final report. Albany Medical College Institute of Experimental Pathology and Toxicology.

3. Tola, S., S. Hernberg, and J. Niklanen. 1973. Parameters indicative of absorption and biological effect in new lead exposure: a prospective study. Br. J. Ind. Med. 30: 134-141.

4. Hursh, J., and J. Suomela. 1968. Absorption of ${ }^{212} \mathrm{~Pb}$ from the gastrointestinal tract of man. Acta. Radiol. 7 : 108-120.
5. Hursh, J., and T. Mercer. 1970. Measurement of ${ }^{212} \mathrm{~Pb}$ loss rates from human lungs. J. Appl. Physiol. 28: 268274.

6. Zieve, L., S. Silvis, B. Mulford, and W. Blackwood. 1966. Secretion of pancreatic enzymes. Am. J. Dig. Dis. 11: 671-684.

7. Rabinowitz, M., G. Wetherill, and J. Kopple. 1973. Lead metabolism in the normal man: Stable isotope studies. Science (Wash. D. C.). 182: 725-727.

8. Kopple, J., and J. Coburn. 1973. Metabolic studies of low protein diets. Medicine (Baltimore). 52: 583-607.

9. Schroeder, H., and I. Tipton. 1968. The human body burden of lead. Arch. Environ. Health. 17: 1965-1977.

10. Wintrobe, M. 1961. Clinical Hematology. Lea and Febiger, Philadelphia. 163.

11. Butt, E., R. Nusbaum, T. Gilmour, S. Didio, and S. Mariano. 1964. Trace metal levels in human serum and blood. Arch. Environ. Health. 8: 52-57.

12. Rabinowitz, M., G. Wetherill, and J. Kopple. 1974. Studies of human lead metabolism by use of stable isotope tracers. Environ. Health Perspect. 7: 143-153.

13. Vostal, J., and J. Heller. 1968. Renal excretory mechanism of heavy metals. Environ. Res. 2: 1-10.

14. Clarkson, T., and J. Kench. 1958. Uptake of lead by human erythrocytes in vitro. Biochem. J. 68: 432-439.

15. Waldron, H., and D. Stöfer. 1974. Sub-clinical lead poisoning. Academic Press Inc., Ltd., London. 58.

16. White, A., P. Handler, and E. Smith. 1968. Principles of Biochemistry. McGraw-Hill Book Company, New York. 814-821.

17. Castellino, N., and S. Aloj. 1964. Kinetics of the distribution and excretion of lead in the rat. Br. J. Ind. Med. 21 : 308-314.

18. Bolanowska, W., and J. Piotrowski. 1968. Kinetics of distribution and excretion of lead $\left({ }^{210} \mathrm{~Pb}\right)$ in rats. II. Excretion of a single intravenous lead dose. Medycyna Pracy. 19 : 133-142.

19. Sattler, E. 1972. Lead intake and distribution. Results of inhalation experiments on small rodents and with humans and ingestion studies with rats. In Blei und Umwelt. Commision für Umweltgefahren des Bungesundheitsamtes. Bonn. 79-83. 